\title{
Disaster Neurology Update
}

\section{Focus on the COVID-19 Pandemic}

Jayaji M. Moré, MD, MS, Justin A. Miller, BS, and Mill Etienne, MD, MPH, FAAN

Neurology: Clinical Practice April 2021 vol. 11 no. 2 175-178 doi:10.1212/CPJ.0000000000001042
Correspondence

Dr. Etienne

Mill_Etienne@nymc.edu

\section{Abstract}

In 2013, the term disaster neurology was introduced to describe a new practice opportunity for neurologists interested in providing needed, nonsurgical neurologic care in regions affected by natural or human-influenced disasters. Although previously presented as an option for interested neurologists, the coronavirus disease 2019 (COVID-19) pandemic has made it clear that every neurologist should be prepared to take on the unique challenges of disaster neurology. Examining the role of neurologists on the frontlines of the COVID-19 pandemic response represents an opportunity to review

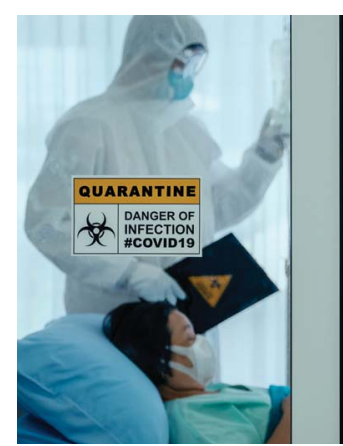
and apply key features of disaster neurology, including recognizing the categories of neurologic cases expected to be seen during a disaster, adapting inpatient and outpatient workflows, and accommodating the needs of vulnerable populations. Relating principles of disaster neurology to the response of neurologists to the current pandemic informs best practices for neurologic care as COVID-19 cases continue to surge throughout the United States and abroad.

A medical disaster occurs when the number of cases caused by a hazard exceeds the local response capacity of a region, leading to a negative effect on health, life, property, or the environment. ${ }^{1}$ Typically, the medical needs of a region affected by a disaster are complex, requiring a multidisciplinary team. Disasters in the past decade that have benefited from the involvement of neurologists include natural disasters, such as the 2010 Haiti earthquake and 2011 Japanese earthquake and tsunami, and military conflicts, such as the ongoing Syrian Civil War. ${ }^{1,2}$

The coronavirus disease 2019 (COVID-19) pandemic caused by severe acute respiratory syndrome coronavirus 2 (SARS-CoV-2) has overwhelmed many local healthcare systems and has necessitated a widespread call to action among neurologists, who have been tasked to identify and manage neurologic manifestations of the disease and transform their clinical practices in unprecedented ways. ${ }^{3}$ COVID-19 cases continue to increase in multiple regions, notably across the United States, Europe, and South America. ${ }^{4}$ Here, we highlight the key principles of disaster neurology for practicing neurologists to consider in responding to the COVID-19 pandemic. Specifically, we focus on the categories of neurologic cases expected, ways to adapt workflow, and considerations for disadvantaged populations.

\section{Categories of Neurologic Cases}

The types of neurologic cases seen during a disaster are divided into 3 categories: cases caused by the disaster, cases caused indirectly or exacerbated by the disaster, and those reflecting background neurologic disease in the community. ${ }^{1}$

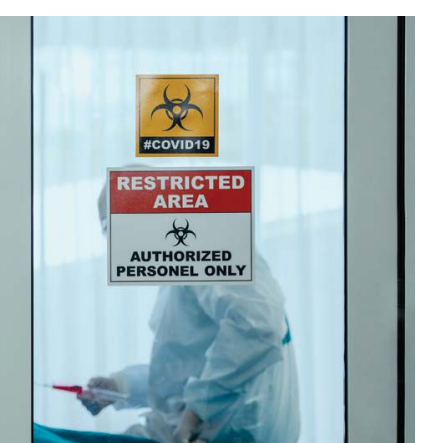

RELATED ARTICLE

\section{Editorial}

Lessons From Disaster

Medicine for the

Neurologist in the

COVID-19 Era:

Going Viral

Page 91

\section{MORE ONLINE}

\section{COVID-19 Resources}

For the latest articles, invited commentaries, and blogs from physicians around the world

NPub.org/COVID19 


\section{Neurologic Cases Caused by the Pandemic}

Neurologic cases caused by the pandemic are represented by direct neurologic manifestations of SARS-CoV-2 or its sequelae. Multiple central and peripheral nervous system presentations of COVID-19 have previously been reported. ${ }^{5}$ Given that COVID-19 may lead to a prothrombotic state, stroke is of particular concern and has been documented as the first symptom of COVID-19 in young patients. ${ }^{6,7}$ In addition, past viral epidemics including $\mathrm{H}_{1} \mathrm{~N}_{1}$ and SARSCoV-1 have shown that delayed neurologic sequelae may arise acutely or weeks to months after infection. Incidences of seizures, narcolepsy, encephalitis, and neuromuscular and demyelinating processes such as Guillain-Barre syndrome were well reported. ${ }^{8-11}$ The extent to which these conditions develop post-COVID-19 infection remains unknown. Over the course of the pandemic, new guidelines and articles describing neurologic manifestations of SARS-CoV-2 have been published frequently. We recommend that neurologists keep up with the rapidly developing literature and adjust their practice accordingly.

\section{Neurologic Cases Indirectly Caused or Exacerbated by the Pandemic}

Neurologists should consider what influence the overarching pandemic may have on preexisting neurologic conditions. Factors such as psychological stress, unemployment, and limited access to doctors or medication may lead to exacerbation of underlying conditions, as was seen with the previous SARS outbreak. $^{12}$ After the 2011 Japan earthquake and tsunami, an increase in the number of patients presenting with seizures was observed. ${ }^{13}$ The COVID-19 crisis may preferentially victimize patients with stress-prone neurologic conditions, such as epilepsy, multiple sclerosis, and migraine. After the 2010 Haiti earthquake, disruption of infrastructure and overcrowding of families increased risk for communicable diseases. Quarantine and social distancing measures may pose similar risks for contraction of COVID-19, particularly in low-income communities. ${ }^{14}$ Quarantine measures may shift the types of neurologic trauma seen by neurologists. Trauma from motor vehicle accidents may decrease, whereas social isolation, economic hardship, and increased alcohol consumption may increase the incidence of domestic violence and child abuse with increased potential for nonaccidental trauma. ${ }^{15}$

Financial stress caused by business closures or unemployment may present a significant barrier for acquiring medication, leading to inadequate management of chronic neurologic conditions. The unemployment rate in the United States reached levels not seen since the Great Depression, peaking at over 14\% in May 2020. ${ }^{16}$ It is conceivable that lost wages or loss of health insurance may force low-income families to choose between food and medication. Nonadherence to anticonvulsants can have devastating consequences, including death. Likewise, suboptimal management of hypertension, diabetes mellitus, and other stroke risk factors may increase patient susceptibility to stroke.
It is worth noting that specific medications administered during the COVID-19 pandemic may contribute to exacerbation of underlying neurologic disease. Hydroxychloroquine and azithromycin are not recommended in patients with myasthenia gravis because this may enhance neuromuscular blockade and provoke myasthenic crisis. In addition, numerous publications have made clear that hydroxychloroquine may harm patients with COVID-19. Established guidelines on the use of triptans in patients with prothrombotic state should be followed.

Finally, precautions must be taken for patients on immunosuppressant therapy. Although consensus guidelines are pending, for neuroimmunologic diseases such as multiple sclerosis requiring disease-modifying immunotherapy, treatment initiation, continuation, and optimization should be continued. ${ }^{17}$ Furthermore, for acute neuroimmunologic emergencies, corticosteroid therapy, plasma exchange, and intravenous immunotherapy is recommended. Neurologists should balance the severity of neuroimmunologic illness with COVID-19 related risk factors when making decisions regarding discontinuation of therapy. When possible, patients with conditions requiring periodic intravenous infusions should receive infusions at home. For those who must travel for treatment, measures should be taken to limit unnecessary contacts.

\section{Background Neurologic Disease in the Community}

Continued provision of neurologic care is required for existing and newly diagnosed cases of epilepsy, Alzheimer disease, Parkinson disease, multiple sclerosis, amyotrophic lateral sclerosis, and other conditions typically managed in the outpatient setting. Regarding stroke, social factors tied to the pandemic, such as social distancing and public fear, may make detection and timely treatment challenging. Furthermore, patients with less severe symptoms may be less motivated to seek care because of employment concerns, loss of insurance, or fear of contracting the virus. In the aftermath of the COVID-19 surge, hospital presentation for stroke-like symptoms decreased, without differences in stroke severity or early outcomes. ${ }^{18-20}$ Neurologists should reinforce to the public the continued importance of timely neurologic care in the event of stroke warning signs.

\section{Adapting Inpatient Workflow}

Engaging in neurologic practice during a disaster requires adapting traditional workflow. Adaptations have centered on need to preserve resources and reduce risk of viral transmission to patients and healthcare workers. In the inpatient setting, if personal protective equipment is limited and the hospital has a large number of patients with COVID-19, inperson neurology consultations can be restricted to those that are urgent or emergent. ${ }^{21}$ Telestroke can be used in the emergency department to avoid unnecessary contacts, and 
this can extend to evaluation of nonstroke presentations, such as new-onset seizures, encephalopathy, and MS exacerbations. ${ }^{22}$ Hospital-to-hospital transfers should be limited, and, when possible, telemedicine should be provided to institutions lacking a particular service line.

Maintaining flexibility is an essential component of disaster response and willingness to work in potentially unfamiliar environments. Inpatient neurology workforces can be reorganized to protect high-risk team members and to optimize redundancy in coverage. ${ }^{22}$ Furthermore, neurologists trained in neurocritical care can be redeployed to work in standard intensive care units, whereas other neurologists may be repurposed to work in the emergency department and on the hospital wards as hospitalists. ${ }^{21}$ Hospitalist and intensivists can provide backup if necessary.

\section{Adapting Outpatient Workflow}

Regions affected by COVID-19 or other disasters should prepare for rapid transition to outpatient teleneurology if possible and postponement of elective procedures such as EEGs, EMGs, and MRIs. During the pandemic, a nearly $60 \%$ decrease in ambulatory visits occurred, which was accompanied by a rapid increase in teleneurology visits. ${ }^{23}$ Teleneurology will require reliance on neurologic exam skills and comfort practicing without access to advanced neurodiagnostics. Low-income populations may not have access to technology needed for teleneurology. ${ }^{24}$ Therefore neurologic problems may go unnoticed in socioeconomically disadvantaged populations which could result in patients delaying care and presenting to clinics and hospitals sicker as the pandemic wanes. In addition, patients who could have been managed via telemedicine may put themselves at unnecessary risk by going to the emergency department for routine evaluations. The successful expansion of teleneurology at many facilities nationally during this pandemic should serve as a model for the provision of remote neurologic care in both disaster and nondisaster scenarios in the future.

\section{Conclusions}

The COVID-19 pandemic has seen a wide spectrum of cases requiring attention from providers with neurologic training. Therefore, a key practical implication is for neurologists to see their value as frontline responders in future disasters. Actions taken by neurologists during the COVID19 pandemic are transferrable to actions required during humanitarian assistance and disaster response missions. Key attributes for neurologists working in disaster settings are adaptability and resourcefulness. It currently remains unanswered the degree to which teleneurology in the outpatient setting during the pandemic will predominate. Furthermore, future work is needed to determine the impact of delays of elective neurologic procedures and the prevalence of direct delayed and indirect neurologic cases caused by COVID-19. Appreciation for the value of the neurologist during the COVID-19 pandemic may encourage neurologists to use their training to volunteer in disaster situations in the future and take additional steps to ensure they are prepared to serve. Representative neurology bodies globally have been rapidly disseminating practical guidelines regarding best practices during the pandemic and may consider drawing from principles of disaster neurology to improve preparation for and management of future responses.

\section{Study Funding}

No targeted funding reported.

\section{Disclosure}

The authors report no disclosures relevant to the manuscript. Full disclosure form information provided by the authors is available with the full text of this article at Neurology.org/cp.

\section{Publication History}

Received by Neurology: Clinical Practice August 12, 2020. Accepted in final form November 30, 2020.

Appendix Authors

\begin{tabular}{lll}
\hline Name & Location & Contribution \\
\hline $\begin{array}{l}\text { Jayaji M. Moré, } \\
\text { MD, MS }\end{array}$ & $\begin{array}{l}\text { New York Medical } \\
\text { College, Valhalla }\end{array}$ & Wrote the initial manuscript \\
\hline Justin A. Miller, BS & $\begin{array}{l}\text { New York Medical } \\
\text { College, Valhalla }\end{array}$ & $\begin{array}{l}\text { Provided critical review of } \\
\text { the manuscript }\end{array}$ \\
\hline $\begin{array}{l}\text { Mill Etienne, MD, } \\
\text { MPH, FAAN }\end{array}$ & $\begin{array}{l}\text { New York Medical } \\
\text { College, Valhalla }\end{array}$ & $\begin{array}{l}\text { Conceptualized the article } \\
\text { and provided critical review } \\
\text { of the manuscript }\end{array}$ \\
\hline
\end{tabular}

\section{References}

1. Etienne M, Alessi AG. Disaster neurology: a new practice opportunity and challenge for the neurologist. Neurol Clin Pract 2013;3:493-500.

2. Etienne M, Tsao JW. Wartime neurology: Serving the neediest in an austere environment. Neurol Clin Pract 2019;9:5-6.

3. Miller IF, Becker AD, Grenfell BT, et al. Disease and healthcare burden of COVID-19 in the United States. Nat Med 2020;26:1212-1217.

4. COVID-19 Dashboard by the Center for Systems Science and Engineering (CSSE) at Johns Hopkins University. August 10, 2020. Available at: coronavirus.jhu.edu/data/ new-cases. Accessed August 10, 2020.

5. Ellul MA, Benjamin L, Singh B, et al. Neurological associations of COVID-19. Lancet Neurol 2020;19:767-783.

6. Sweid A, Hammoud B, Weinberg J, et al. Letter: thrombotic neurovascular disease in COVID-19 patients. Neurosurgery 2020;87:E400-E406.

7. Koralnik IJ, Tyler KL. COVID-19: a global threat to the nervous system. Ann Neurol 2020;88:1-11.

8. Kim JE, Heo JH, Kim HO, et al. Neurological complications during treatment of middle east respiratory syndrome. J Clin Neurol 2017;13:227-233.

9. Wu H, Zhuang J, Stone WS, et al. Symptoms and occurrences of narcolepsy: a retrospective study of 162 patients during a 10-year period in Eastern China. Sleep Med 2014;15:607-613.

10. Tsai LK, Hsieh ST, Chao CC, et al. Neuromuscular disorders in severe acute respiratory syndrome. Arch Neurol 2004;61:1669-1673.

11. Manjunatha N, Math SB, Kulkarni GB, et al. The neuropsychiatric aspects of influenza/swine flu: a selective review. Ind Psychiatry J 2011;20:83-90.

12. Sim K, Chan YH, Chong PN, et al. Psychosocial and coping responses within the community health care setting towards a national outbreak of an infectious disease. J Psychosom Res 2010;68:195-202.

13. Shibahara I, Osawa S, Kon H, et al. Increase in the number of patients with seizures following the Great East-Japan Earthquake. Epilepsia 2013;54:e49-e52. 
14. Centers for Disease Control and Prevention. Rapid establishment of an internally displaced persons disease surveillance system after an earthquake: Haiti, 2010. MMWR Morb Mortal Wkly Rep 2010;59:939-945.

15. Huang MI, O’Riordan MA, Fitzenrider E, et al. Increased incidence of nonaccidental head trauma in infants associated with the economic recession. Pediatrics 2011;8:171.

16. U.S. Department of Labor, Bureau of Labor Statistics. The Employment Situation-May 2020. 2020. Available at: bls.gov/news.release/pdf/empsit.pdf. Accessed July 1, 2020

17. Korsukewitz C, Reddel SW, Bar-Or A, et al. Neurological immunotherapy in the era of COVID-19-looking for consensus in the literature. Nat Rev Neurol 2020;16:493-505.

18. Jasne AS, Chojecka P, Maran I, et al. Stroke code presentations, interventions, and outcomes before and during the COVID-19 pandemic. Stroke 2020;51:2664-2673.

19. Kansagra AP, Goyal MS, Hamilton S, et al. Collateral effect of Covid-19 on stroke evaluation in the United States. N Engl J Med 2020;383:400-401.
20. ange SJ, Ritchey MD, Goodman AB, et al. Potential indirect effects of the COVID-19 pandemic on use of emergency departments for acute life-threatening conditionsUnited States, January-May 2020. MMWR Morb Mortal Wkly Rep 2020;69:795-800.

21. Waldman G, Mayeux R, Claassen J, et al. Preparing a neurology department for SARS-CoV2 (COVID-19): early experiences at Columbia University Irving Medical Center and the New York Presbyterian Hospital in New York City. Neurology 2020;94:886-891.

22. Majersik JJ, Reddy VK. Acute neurology during the COVID-19 pandemic: supporting the front line. Neurology 2020;94:1055-1057.

23. Mehrotra A, Chernew M, Linetsky D, et al. The impact of the COVID-19 pandemic on outpatient visits: a rebound emerges. To the Point (blog), Commonwealth Fund, May 19, 2020

24. Vazquez J, Islam T, Gursky J, et al. Access to care matters: remote health care needs during COVID-19. Telemed J E Health Epub 2020 Sep 30.

\section{Share Your Insights, Expertise, and Experiences}

- How are you employing drugs and devices in your field?

- What ethical challenges do you face?

- Do you have a case report that is illustrative of a clinical challenge?

- What challenges have you faced or successes have you enjoyed in bringing greater efficiency to your practice?

Deliver a high-quality, peer-reviewed message to your colleagues in practice, submit your paper at NPub.org/NCP/submit. 


\section{Neurology Clinical Practice}

Disaster Neurology Update: Focus on the COVID-19 Pandemic

Jayaji M. Moré, Justin A. Miller and Mill Etienne

Neurol Clin Pract 2021;11;175-178 Published Online before print January 25, 2021

DOI 10.1212/CPJ.0000000000001042

This information is current as of January 25, 2021

Updated Information \&
Services

References

Citations

Subspecialty Collections

Permissions \& Licensing

Reprints including high resolution figures, can be found at:

http://cp.neurology.org/content/11/2/175.full.html

This article cites 20 articles, 2 of which you can access for free at: http://cp.neurology.org/content/11/2/175.full.html\#\#ref-list-1

This article has been cited by 1 HighWire-hosted articles: http://cp.neurology.org/content/11/2/175.full.html\#\#otherarticles

This article, along with others on similar topics, appears in the following collection(s):

All Clinical Neurology

http://cp.neurology.org//cgi/collection/all_clinical_neurology

COVID-19

http://cp.neurology.org//cgi/collection/covid_19

Public health

http://cp.neurology.org//cgi/collection/public_health

Underserved populations

http://cp.neurology.org//cgi/collection/underserved_populations

Information about reproducing this article in parts (figures,tables) or in its entirety can be found online at:

http://cp.neurology.org/misc/about.xhtml\#permissions

Information about ordering reprints can be found online:

http://cp.neurology.org/misc/addir.xhtml\#reprintsus

Neurol Clin Pract is an official journal of the American Academy of Neurology. Published continuously since 2011, it is now a bimonthly with 6 issues per year. Copyright $\odot 2021$ American Academy of Neurology. All rights reserved. Print ISSN: 2163-0402. Online ISSN: 2163-0933.

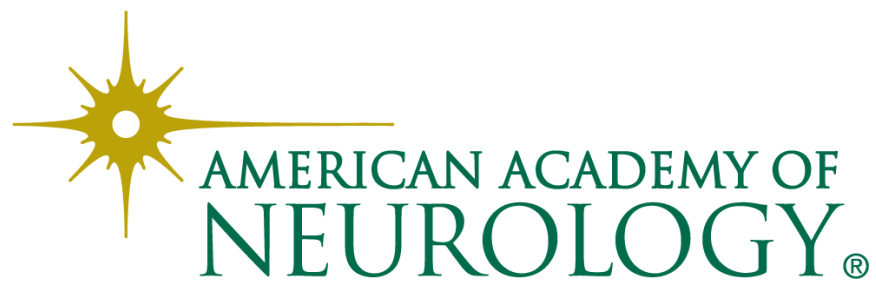

